\title{
Phytobezoar: Impact of Differential Diagnosis and Difficulties in Technical Diagnostics
}

\author{
Comment on: Park JW, Chae HD: Phytobezoar of the Stomach. Dig Surg 2009;26:451-452.
}

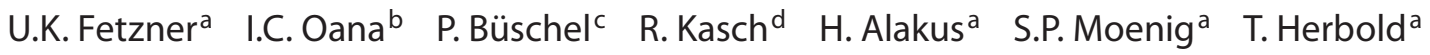 \\ D.L. Stippel ${ }^{\mathrm{a}} \quad$ J. Scheele ${ }^{\mathrm{b}}$ \\ ${ }^{a}$ Department of General, Visceral and Cancer Surgery, University of Cologne, Cologne, ${ }^{b}$ Department of General \\ and Visceral Surgery, Clinic Bad Hersfeld, Bad Hersfeld, 'Department of General, Abdominal and Vascular Surgery, \\ University Hospital Magdeburg, Magdeburg, and ${ }^{\mathrm{d} C l i n i c}$ and Outpatient Clinic for Orthopaedics and Orthopaedic \\ Surgery, University Clinic of Greifswald, Greifswald, Germany
}

\section{Dear Sir,}

We read the article 'Phytobezoar of the stomach' by Park and Chae [1] with great interest. Despite the fact that the literature published on the matter is rare, with only a small number of case reports, the clinical incidence of phytobezoar seems not to be that rare in reality. I will cite here one case relevant from this point of view and which will be published shortly: we noticed a cherry pit ileus of the colon ascendens, which had been causing abdominal pain for a long period. Many previous clinical and technical examinations like endoscopy and even CT scan did not lead us to the correct diagnosis. When the patient was admitted to our hospital, we had a strong suspicion of an obstructing malignant tumor and performed a right hemicolectomy.
For the diagnosis of phytobezoar, it is good to examine the stomach by endoscopy. In contrast, for the lower parts of the intestinal tract, the diagnosis can be challenging and the visible structure will frequently be impossible to distinguish from a tumor mass $[2,5]$.

Risk factors for the development of a phytobezoar are previous resections/reconstructions in the intestinal tract, stenosis (e.g. Crohn's disease, tumor), disturbances of the GI motility, abnormal diet or vegetarianism $[3,4]$. The localization can be in all parts of the intestinal tract. Severe complications can be an ileus or even a perforation of the intestinal wall [3].

Chemical dissolution and especially endoscopic treatment can be an appropri- ate initial treatment option for gastric bezoar. If this does not lead to success - especially in the case of bezoar occurring in other parts of the intestinal tract - surgical treatment will often be unavoidable [5].

We are, once again, thankful to the authors for this important and interesting case report. In our view, the two main aspects of this entity are exposed in a most clear and concise manner, i.e. keeping bezoar in mind during differential diagnosis - especially when risk factors are present - and considering the difficulties of technical diagnostics.

\section{References}

1 Park JW, Chae HD: Phytobezoar of the stomach. Dig Surg 2009;26:451-452.

2 Zissin R, Osadchy A, Gutman V, Rathaus V, Shapiro-Feinbeg M, Gayer G: CT findings in patients with small bowel obstruction due to phytobezoar. Emerg Radiol 2004;10:197200.

3 Kvitting JP, Andersson P, Druvefors P: A phytobezoar in acute abdomen. Am J Surg 2009;197:e21-e22.
4 Lee SJ, Chu SJ, Tsai SH: Colonic phytobezoar. Emerg Med J 2007;24:518.

5 De Menezes Ettinger JE, Silva Reis JM, De Souza EL, Filho Ede M, Galvao do Amaral PC, Ettinger E Jr, Fahel E: Laparoscopic management of intestinal obstruction due to phytobezoar. JSLS 2007;11:168-171.

\section{KARGER \\ Fax +4161306 1234 E-Mail karger@karger.ch} www.karger.com
Ulrich Klaus Fetzner

Department of General, Visceral and Cancer Surgery

University of Cologne, Kerpener-Strasse 62

DE-50937 Cologne (Germany)

Tel. +49 221478 89490, Fax +49221 478 86104, E-Mail ulrich.fetzner@uk-koeln.de 